Open Access

\title{
On entrepreneurial decision logics under conditions of uncertainty: an attempt to advance the current debate
}

\author{
David J. Rapp ${ }^{1}$ (D) and Michael Olbrich ${ }^{2^{*}}$ (D)
}

\author{
* Correspondence: olbrich@iwp.uni- \\ saarland.de \\ ${ }^{2}$ Institute of Auditing, Saarland \\ University, Saarbrücken, Germany \\ Full list of author information is \\ available at the end of the article
}

\begin{abstract}
Uncertainty plays a crucial role for most entrepreneurship theories and is thus at the core of entrepreneurship research. Despite decades of research efforts, the notion of uncertainty is still somewhat vague and elusive, however. Consequently, desirable improvement of our understanding of uncertainty requires further considerations. Fortunately, in a recent paper published in the Academy of Management Review, Packard and Clark (Academy of Management Review, 2019) contribute their ideas on the subject. The study in question offers a novel dichotomy of uncertainty types and normatively prescribes entrepreneurial strategies associated with those different settings. The remarks of Packard and Clark have attracted opposition, however, and while appreciating the study's efforts to refine the uncertainty construct, the present paper aims to advance the current debate. One stance adopted in the current paper to do so is to suggest supplementing research on uncertainty itself with the notion of ill-structuredness affecting decision problems. That approach makes it possible to theorize about entrepreneurial decision-making in a broader yet more nuanced way.

Keywords: Entrepreneurship, Decision-making, Uncertainty, IIl-structuredness
\end{abstract}

\section{Introduction}

"Because entrepreneurship is reasoned action in uncertainty" (Packard et al. 2017: 841), entrepreneurship research has focused on issues surrounding uncertainty ever since Knight's seminal contribution Risk, Uncertainty, and Profit in 1921 (Townsend et al. 2018; Welter and Kim 2017). Herbener (1992: 80-81) expounded on the meaning of uncertainty: "If the future state of affairs were known in advance with deterministic certainty, human action would be negated...Uncertainty as a condition of human action lies between determinism and randomness, and implies the human capacity to form expectations of the future that do not diverge completely from it nor adhere completely to it."

Knight (1921) fundamentally distinguished three types of probabilities, referring to two of them (a priori and statistical) as risk while associating the remaining one (estimates) with the term uncertainty. The key distinctive feature between Knightian risk and Knightian uncertainty is the accessibility of somewhat objective probabilities. They

(c) The Author(s). 2020 Open Access This article is licensed under a Creative Commons Attribution 4.0 International License, which permits use, sharing, adaptation, distribution and reproduction in any medium or format, as long as you give appropriate credit to the original author(s) and the source, provide a link to the Creative Commons licence, and indicate if changes were made. The images or other third party material in this article are included in the article's Creative Commons licence, unless indicated otherwise in a credit line to the material. If material is not included in the article's Creative Commons licence and your intended use is not permitted by statutory regulation or exceeds the permitted use, you will need to obtain permission directly from the copyright holder. To view a copy of this licence, visit http://creativecommons.org/licenses/by/4.0/. 
either exist a priori or can be derived statistically by means of grouping together similar observable incidents (risk), or the uniqueness of a particular event renders the computation of an objective probability impossible (uncertainty), thus demanding decisionmakers exercise judgment. Knightian uncertainty is the key prerequisite for the emergence of profits (Barney 1986; von Mises 1949) and, hence, acutely central to the study and understanding of the phenomenon of entrepreneurship as profits are the reward for good entrepreneurial judgment (Knight 1921). This holds true for both start-up and well-established firms albeit the uncertainty they face might differ in degree (e.g., Brösel et al. 2012).

Among other things, entrepreneurship research has established various uncertainty conceptualizations (Dequech 2011; Dosi and Egidi 1991; Kahneman and Tversky 1982; Milliken 1987; Packard et al. 2017) attempting to decipher, in particular, where, how, and why uncertainty occurs, and how it shapes entrepreneurial decision-making. The stated purpose of Packard et al. (2017: 841), for instance, is "clarifying how, why, and in what ways different decision contexts are uncertain." This last study constructs its framework - that encompasses situations of risk/ambiguity, creative uncertainty, environmental uncertainty, and absolute uncertainty-based on the openness or closedness of the entrepreneurial sets of options and outcomes. Most recently, research has emphasized the necessity for additional considerations directed toward a more nuanced notion of uncertainty (Townsend et al. 2018). Congruously, in a recent Academy of Management Review piece entitled "On the Mitigability of Uncertainty and the Choice between Predictive and Non-Predictive Strategy," Packard and Clark (2019: 2) propose another distinction between uncertainty types and argue that doing so will "produce important theoretical nuance and key boundary conditions in the normative choice between predictive and non-predictive strategies." The authors identify epistemic (mitigable) and aleatory (immitigable) uncertainties as distinct categories and essentially reason that decision-makers should prefer predictive approaches under conditions of epistemic uncertainty while suggesting entrepreneurs use adaptive, incremental approaches in the presence of aleatory uncertainty.

Uncertainty in general, and Packard and Clark (2019) in particular, warrant further discussion; Packard and Clark's paper has already attracted comments on various grounds. Arend (2020: 702) mocks "the irony of being certain on how to deal with uncertainty," and considers it logically impossible to prescribe in general terms what kind of logic an entrepreneur should prefer in a situation of immitigable uncertainty. Rather than attempting to provide general normative guidance, Arend suggests, "getting more specific on the contexts and problems in ways that can better isolate the immitigabilities or the possible choices or both" (Arend 2020: 703). In their subsequent reply, Packard and Clark (2020a: 707) counter that "prescriptions [of decision logics], such as those put forth in effectuation theory, are very possible once you have the meta-theory right."

Holmes and Westgren (2020) also comment on Packard and Clark (2019). However, they focus on a different aspect of the latter's reasoning choosing to direct attention particularly to Packard and Clark's typology and arguing that mitigable and immitigable uncertainty do not map well onto their claimed pendants epistemic and aleatory uncertainty respectively, as Packard and Clark (2019) state they do. For this reason, Holmes and Westgren in particular suggest reshaping the boundaries between epistemic and aleatory uncertainty. While Packard and Clark (2020b: 4) "find this proposition 
intriguing and...advantageous in some respects," they, however, consider it "disadvantaged in others."

As Packard and Clark (2020b: 8) expressly remain "open to further conversation," the present paper seeks to build on and advance the ongoing debate by acknowledging both Packard and Clark's (2019; 2020a; 2020b) work and the criticisms leveled against it (Arend 2020; Holmes and Westgren 2020). Similarly to Packard and Clark (2020a: 2) who emphasize that they "easily acknowledge that there are reasons to disagree with our conclusions," we find it not unreasonable that the critics take umbrage with Packard and Clark's (2019) ideas, and for two reasons in particular: First, the boundary conditions of the presented uncertainty distinctions seem ambiguous, both internally (as indicated by Holmes and Westgren (2020)) and in relation to Knight's (1921) wellestablished and widely accepted distinction between uncertainty and risk. Second, it seems disputable whether Packard and Clark's (2019) normative approach is indeed suited to their specific analysis of entrepreneurial decision-making. We are afraid that a normative prescription of preferable decision logics is unsustainable, albeit for reasons other than probabilistic logic as suggested by Arend (2020).

We emphatically appreciate efforts to advance the understanding of the uncertainty construct. Hence, the proposals to advance the debate we provide in this paper must not be misinterpreted as a criticism of attempts to research uncertainty and its particular impacts on entrepreneurial decision-making. While emphasizing the fundamental importance of researching uncertainty, the current paper goes one step further in that it suggests supplementing the notion of uncertainty developed in entrepreneurship research, and its most recent manifestation as suggested by Packard and Clark (2019) in particular, with the broader notion of ill-structuredness of decision problems (Simon and Newell 1958) known from normative decision theory. Doing so makes it possible to better conceptualize the complete range of knowledge problems (Townsend et al. 2018) entrepreneurs face, inclusive of uncertain options and/or outcomes.

\section{Epistemic vs. aleatory uncertainty}

A central tenet of the argument made by Packard and Clark (2019) is differentiating epistemic uncertainty from aleatory uncertainty. While the former is defined "in terms of its mitigability-that is, uncertainty is, for us, epistemic if it results from ignorance of knowledge that is knowable in principle" (Packard and Clark 2019: 9), the latter "is characterized by its immitigability. It is uncertainty not characterized by ignorance of knowable information, but by immitigable ignorance" (Packard and Clark 2019: 11). The aforementioned is the case "inasmuch as and to the extent that other human actors have influence over the outcome" (Packard and Clark 2019: 26). Based on that distinction, Packard and Clark (2019: 28) argue that in "general, managers and entrepreneurs facing epistemic uncertainty should, normatively, tend towards causal logics," whereas in "aleatory uncertainty...non-predictive strategy is generally preferable" (Packard and Clark 2019: 27).

\section{Uncertainty, risk, and (im)mitigability}

Knight's (1921) distinction of risk and uncertainty has undoubtedly influenced entrepreneurship research on this subject more than any other. Packard and Clark (2019), however, do not explicate how their proposal either builds on or categorically refutes 
Knight's seminal concept and, in particular, whether epistemic and aleatory uncertainty are meant to be distinct categories of Knightian uncertainty or whether they fundamentally challenge Knight's dichotomy.

Packard and Clark (2019: 26) suggest that both epistemic and aleatory uncertainty do not fall within the scope of Knightian risk, i.e., they can be interpreted as subcategories of Knightian uncertainty. However, when describing the nature of epistemic uncertainty earlier in the paper, the authors utilize the example of a coin flip. This is somewhat confusing as a coin flip is usually considered a prototypical example of Knightian risk in the form of a priori probabilities (e.g., Foss and Klein 2012). Therefore, while epistemic and aleatory uncertainty are claimed to exist beyond Knightian risk, epistemic uncertainty seems to at least overlap with it. Moreover, epistemic uncertainty is defined in terms of its mitigability being its distinguishing feature; however, as "risk is, inherently, mitigable" (Packard and Clark 2019: 10) too, it remains unclear how both epistemic uncertainty and Knightian risk interrelate.

Apart from its ambiguous relation to Knight's (1921) popular dichotomy, the suggested distinction of epistemic and aleatory uncertainty seems indistinct internally. Again, Packard and Clark (2019) define both epistemic and aleatory uncertainty in terms of their mitigability or otherwise and label epistemic uncertainty mitigable uncertainty and aleatory uncertainty immitigable uncertainty. However, the authors (p. 29) likewise emphasize that uncertainty's "immitigability, practically speaking, includes both aleatory uncertainties as well as those epistemic uncertainties that are beyond the human and technological capabilities that can feasibly be employed to the task of mitigation." Therefore, epistemic uncertainty is supposed to include both uncertainties that are mitigable and uncertainties that are immitigable. Neither mitigability nor immitigability can therefore serve as a feature distinguishing the proposed uncertainty types. The two suggested categories are not distinct from each other; they overlap.

\section{Uncertainty types or problem structure?}

In their decision-making, entrepreneurs are confronted with more than just uncertainty regarding both options and outcomes, as entrepreneurship research generally holds (e.g., Townsend et al. 2018). There are knowledge problems (Townsend et al. 2018) beyond uncertainty thus defined and Packard and Clark (2019: 8-9) also note their influence. One way of organizing entrepreneurial knowledge problems is to refer to the structure of decision problems as developed by normative decision theory.

Four fundamental elements describe the structure of decision problems (Arrow 1951; Langlois 1982; Simon and Newell 1958; Wilson and Alexis 1962). The first is a closed set of means, i.e., a set that comprises both all the decision-maker's options and their outcomes. The second is an appraisement serving to reduce the options' outcomes to a common and, hence, comparable denominator as the precursor to choosing an option. The third is an objective function enabling the decision-maker ultimately to choose the option that most effectively meets the desired end(s). The fourth is the existence of algorithms providing the decision-maker with a solution via a computational routine. When those four elements are present, the decision problem is "well structured" (Simon and Newell 1958: 4), which enables the decision-maker to select the optimal solution to the problem by making a so-called rational choice (Ariely 2009; 
Kahneman and Tversky 1979; Miller 2007; von Neumann and Morgenstern 1944; Savage 1954; Simon 1976).

However, entrepreneurs make specific decisions, predominantly acting in contexts where well-structured problems are rare, if present at all. The absence of at least one of the premises causes a structural defect and, consequently, results in an ill-structured decision problem (Newell 1969; Reitman 1964; Simon 1973; Simon and Newell 1958). Structural defects and the resulting ill-structuredness can be defining characteristics of entrepreneurial decision problems, whether they concern resource combinations, venture creations, perceived opportunities, or suchlike. Rather than choosing an optimal path, ill-structuredness urges entrepreneurs to exercise judgment involving estimation, imagination, intuition, etc. (Foss and Klein 2012; Foss and Klein 2015; Klein 2008; Klein 2010; Knight 1921; von Mises 1942; Packard et al. 2017).

Because each defect (causality, appraisement, goal, solvability) results from a different source (unknown options and/or outcomes, lack of expertise to appraise different outcomes, unknown or competing ends, or the lack of an algorithm to find the best solution), a defect-oriented view makes it possible to devise a broad framework both to analyze different types of ill-structuredness and to conceptualize possible entrepreneurial tactics to cope with ill-structured problems. For instance, the more strongly a particular entrepreneur perceives a problem to be ill-structured, the more that entrepreneur might prefer non-causal logics, particularly effectuation, over causal logics (Sarasvathy 2001; Bhowmick 2015). Table 1 (which builds on Packard et al.'s (2017)

Table 1 Structural defects compared to typologies of uncertainty in the literature

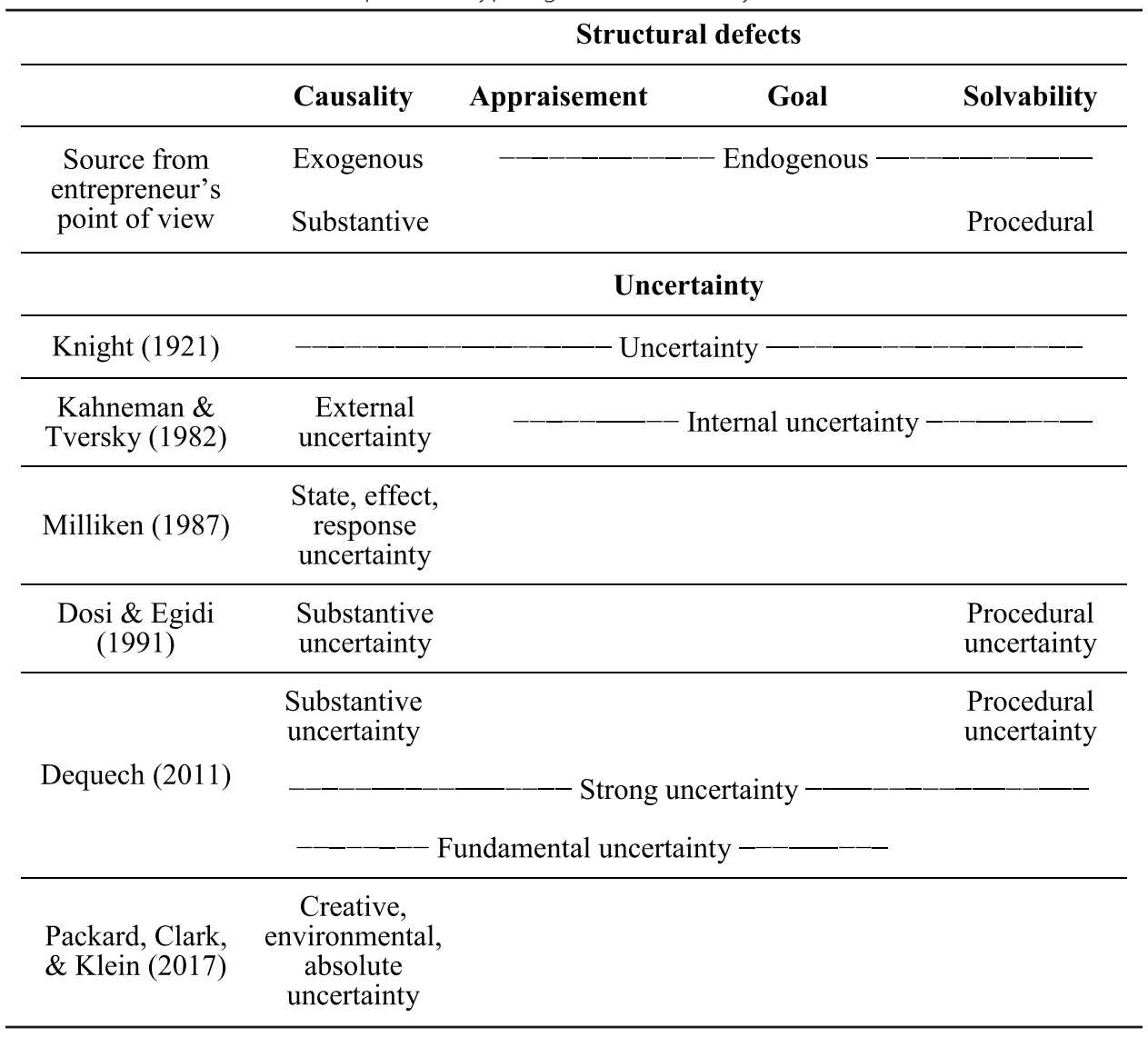


comparison of uncertainty typologies) offers an overview of the relation of some uncertainty distinctions found in the literature and the notion of ill-structuredness. The summary reveals that most of the taxonomies either focus on the uncertain effects of entrepreneurial action or exclusively consider uncertain options and/or outcomes while disregarding other structural defects entrepreneurs (may) have to deal with. While those contributions have spurred considerable progress in conceptualizing the uncertainty construct, we believe a more comprehensive approach via ill-structuredness promises valuable additional insights.

The conceptual idea provided by Packard and Clark (2019) in some sense resembles the above presented framework based on the structure of decision problems. The authors similarly identify that their uncertainty types can arise from entrepreneurs themselves (limited information on particular events; epistemic), from computational issues (epistemic), or from the actions of other human beings (aleatory). However, the Packard and Clark framework (as is the case with the adjustment proposed by Holmes and Westgren (2020)) does not consider further knowledge problems on the part of entrepreneurs themselves associated with both the need for an economizing appraisement of action alternatives and the issue of being confronted with either unknown or competing ends. Including the concept of ill-structuredness in a comprehensive way would encourage research to take account of not only what Packard and Clark (2019) define as epistemic and aleatory uncertainty but also issues confronting entrepreneurs' decision-making beyond that. A recollection of the valuable concept of ill-structuredness hence promises to provide deeper insights into entrepreneurial decision-making than additional distinctions of types of uncertainty alone. Accordingly, we urge the scientific community not to restrict its attention to uncertainty per se and suggest it would be beneficial to both entrepreneurship and related fields such as strategic management to embrace a wider defect-oriented view of entrepreneurial (and managerial) decision-making.

\section{Normativity and entrepreneurial decision-making}

Packard and Clark ultimately aim to investigate, "when non-predictive strategies would be normatively preferable over predictive strategies" (Packard and Clark 2019: 4-5, emphasis added). However, Arend (2020: 703) counters, "that theoretical prescriptions for better dealing with immitigable uncertainty should not be attempted, as logic appears to indicate it is not possible." We certainly acknowledge Packard and Clark's (2020a) rebuttal; we are concerned, however, that in a manner similar to how both uncertainty and ill-structuredness can only be understood in terms of their subjective perception by a particular decision-maker, the selection of a corresponding decision logic is a highly subjective act too. For instance, uncertainty's mitigability may be determined by technical or economic considerations: While the former are indeed quite objective and might only change throughout time by means of technological progress, the latter are highly subjective. Because the value of any particular action differs from one person to another (e.g., von Mises 1949), mitigating uncertainty that is mitigable in principle may seem worthwhile to one entrepreneur but not to another. Hence, attempts to determine whether a decision-maker should prefer one decision logic over another in a particular decision situation, inevitably tend to hit an impasse.

Packard and Clark (2019: 37) too acknowledge the implausibility of general normative guidance on the application of a particular decision logic. They argue that the selection of a 
decision logic is moderated in both epistemic and aleatory uncertainty by either a cost/benefit-analysis or a low risk of loss respectively. For instance, Packard and Clark (2019: 33) disqualify the reasons that prompt an entrepreneur to apply a predictive strategy in conditions of epistemic uncertainty even if a cost/benefit-analysis reveals it not to be worthwhile mitigating uncertainty on the grounds of "biasing the decision." However, is it really a biased decision if an entrepreneur seeks external funding for venture creation and an external financier demands that she mitigate uncertainty and apply causal logics despite the entrepreneur's cost/ benefit-analysis? Could it not be normatively best to refer to causal logics in this exemplary case?

With regard to aleatory uncertainty, Packard and Clark (2019) argue that a low level of risk moderates the decision to apply either predictive or adaptive logics. They approve a deviation from normative guidance to make use of adaptive strategy in aleatory uncertainty whenever the entrepreneur has little to lose anyway. However, which decision logic do the authors believe is normatively best if risk of loss is indeed considered low in conditions of aleatory uncertainty-is it still preferable to stick to adaptive logics or is it better to apply predictive logic instead? We are afraid there is no general normative guidance available in this case either.

Despite their efforts to further specify which decision logic is generally preferable in either of the two uncertainty types, ultimately, Packard and Clark (2019: 37) conclude: "In the end, however, it seems we must leave the answer to this riddle for managers to decide," a statement that indicates how confined a normative approach is for the selection of an (entrepreneurial) decision logic in a particular setting.

\section{Conclusion}

Entrepreneurship scholars increasingly call for more precision, nuance, and a more accurate conceptualization of uncertainty in entrepreneurship theory (Packard et al. 2017; Ramoglou and Tsang 2016; Townsend et al. 2018). Packard and Clark's (2019) distinction of aleatory and epistemic uncertainty can be welcomed as one attempt to better conceptualize uncertainty. The current paper suggests supplementing it with a coherent distinction of structural defects potentially describing entrepreneurial decision problems: Doing so offers two advantages; first, it avoids the outlined ambiguities; and second, it makes it possible to theorize on entrepreneurial decision-making in a broader but more nuanced fashion.

While striving to present a well-grounded recommendation on the application of either adaptive or predictive strategies in different uncertain settings, Packard and Clark (2019) ultimately conclude that the choice between the two logics is best left to the actual decision-maker. We wholeheartedly agree. If each action is the outcome of a subjective valuation, as von Mises (1949) in particular argued, a normative prescription seems limited to an insight already embedded in the very notion of action: Decision-makers should apply the particular decision logic (mitigating uncertainty or otherwise) they subjectively prefer, depending upon how they perceive the circumstances they find themselves in.

We hope the current paper contributes to advancing the debate on entrepreneurial decision-making under uncertainty. Needless to say, however, that debate is anything but settled. Therefore, we would strongly urge the scientific community to intensify its scrutiny of the phenomenon of uncertainty and the role additional structural defects play in entrepreneurial decision-making. 
Abbreviations

e.g.: For example; etc.: And others; i.e.: That is; p.: Page

\section{Acknowledgements}

The authors wish to sincerely thank an anonymous reviewer for providing valuable comments that allowed them to improve the paper.

\section{Authors' contributions}

DR made substantial contributions to this manuscript by developing its conception and argumentation, establishing both the first draft and the revised version, and eventually approving the final, i.e., submitted version. MO made substantial contributions to this manuscript by developing its conception and argumentation, revising the first draft, and both revising and eventually approving the final, i.e., submitted version.

\section{Funding}

This research did not receive any specific grant from funding agencies in the public, commercial, or not-for-profit sectors.

\section{Availability of data and materials}

Not applicable.

\section{Competing interests}

The authors declare that they have no competing interests.

\section{Author details}

'Law, Economics, and Finance Department, Institut Mines-Télécom Business School; Research Lab LITEM, Université Paris-Saclay, Univ. Evry, IMT-BS, Evry, France. ${ }^{2}$ Institute of Auditing, Saarland University, Saarbrücken, Germany.

Received: 2 April 2020 Accepted: 18 August 2020

Published online: 25 September 2020

\section{References}

Arend, R. (2020). On the Irony of Being Certain on How to Deal with Uncertainty. Acad Manag Rev, 45, 702-704.

Ariely, E. (2009). Predictably Irrational: The Hidden Forces That Shape Our Decisions. New York: Harper Collins.

Arrow, K. J. (1951). Social choice and individual values. New York: Wiley.

Barney, J. B. (1986). Strategic Factor Markets: Expectations, Luck, and Business Strategy. Manag Sci, 32, 1231-1241.

Bhowmick, S. (2015). They look while they leap: Generative co-occurrence of enactment and effectuation in entrepreneurial action. J Manag Organ, 21, 515-534.

Brösel, G., Matschke, M. J., \& Olbrich, M. (2012). Valuation of entrepreneurial businesses. Int J Entrep Ventur, 4, 239-256.

Dequech, D. (2011). Uncertainty: A Typology and Refinements of Existing Concepts. J Econ Iss, 45, 621-640.

Dosi, G., \& Egidi, M. (1991). Substantive and procedural uncertainty. J Evol Econ, 1, 145-168.

Foss, N. J., \& Klein, P. G. (2012). Organizing Entrepreneurial Judgment. Cambridge: Cambridge University Press.

Foss, N. J., \& Klein, P. G. (2015). Introduction to a forum on the judgment-based approach to entrepreneurship: Accomplishments, challenges, new directions. J Inst Econ, 11, 1-15.

Herbener, J. M. (1992). The Role of Entrepreneurship in Desocialization. Rev Aust Econ, 6, 79-93.

Holmes, T., \& Westgren, R. (2020). Carving the Nature of Uncertainty at its Joints. Acad Manag Rev in press.

Kahneman, D., \& Tversky, A. (1979). Prospect theory: An analysis of decision under risk. Econometrica, 47, 263-291.

Kahneman, D., \& Tversky, A. (1982). Variants of uncertainty. Cognition, 11, 143-157.

Klein, P. G. (2008). Opportunity Discovery, Entrepreneurial Action, and Economic Organization. Strateg Entrep J, 2, 175-190.

Klein, P. G. (2010). The Capitalist and the Entrepreneur. Auburn: Mises Institute.

Knight, F. H. (1921). Risk, Uncertainty, and Profit. Boston: Houghton Mifflin Co.

Langlois, R. N. (1982). Subjective probability and subjective economics. New York: New York University.

Miller, K. D. (2007). Risk and rationality in entrepreneurial processes. Strateg Entrep J, 1, 57-74.

Milliken, F. J. (1987). Three Types of Perceived Uncertainty about the Environment: State, Effect, and Response Uncertainty. Acad Manag Rev, 12, 133-143.

Newell, A. (1969). Heuristic programming: Ill-structured problems. In J. Aronofsky (Ed.), Progress in operations research (Vol. 3), (pp. 360-414). New York: Wiley.

Packard, M. D., \& Clark, B. B. (2019). On the Mitigability of Uncertainty and the Choice between Predictive and Non-Predictive Strategy. Acad Manag Rev in press.

Packard, M. D., \& Clark, B. B. (2020a). Probability Logic Fails in Immitigable Uncertainty, But Strategic Logic Does Not. Acad Manag Rev, 45, 704-707.

Packard, M. D., \& Clark, B. B. (2020b). Mitigating versus Managing Epistemic and Aleatory Uncertainty. Acad Manag Rev in press.

Packard, M. D., Clark, B. B., \& Klein, P. G. (2017). Uncertainty Types and Transitions in the Entrepreneurial Process. Organ Sci, 28, $840-856$.

Ramoglou, S., \& Tsang, E. W. K. (2016). A Realist Perspective of Entrepreneurship: Opportunities As Propensities. Acad Manag Rev, 41, 410-434.

Reitman, W. R. (1964). Heuristic decision procedures, open constraints, and the structure of ill-defined problems. In M. W. Shelley, \& G. L. Bryan (Eds.), Human Judgments and Optimality, (pp. 282-315). New York: Wiley.

Sarasvathy, S. D. (2001). Causation and Effectuation: Toward a Theoretical Shift from Economic Inevitability to Entrepreneurial Contingency. Acad Manag Rev, 26, 243-263.

Savage, L. J. (1954). Foundations of Statistics. Oxford: Wiley.

Simon, H. A. (1973). The Structure of III Structured Problems. Artif Intell, 4, 181-201. 
Simon, H. A. (1976). Administrative Behavior, (4th ed.). New York: The Free Press.

Simon, H. A., \& Newell, A. (1958). Heuristic problem solving: The next advance in Operations Research. Oper Res, 6(1), 1-10. Townsend, D. M., Hunt, R. A., McMullen, J. S., \& Sarasvathy, S. D. (2018). Uncertainty, Knowledge Problems, and Entrepreneurial Action. Acad Manag Ann, 12, 659-687.

von Mises, L. (1942). Social Science and Natural Science. J Soc Philos Jurisprudence, 7, 240-253.

von Mises, L. (1949). Human Action. New Haven: Yale University Press.

von Neumann, J., \& Morgenstern, O. (1944). Theory of Games and Economic Behavior. Princeton: Princeton University Press. Welter, C., \& Kim, S. (2017). Effectuation under risk and uncertainty: A simulation model. J Bus Ventur, 33, 100-116.

Wilson, C. Z., \& Alexis, M. (1962). Basic Frameworks for Decisions. J Acad Manag, 5, 150-164.

\section{Publisher's Note}

Springer Nature remains neutral with regard to jurisdictional claims in published maps and institutional affiliations.

Submit your manuscript to a SpringerOpen ${ }^{\circ}$ journal and benefit from:

- Convenient online submission

- Rigorous peer review

- Open access: articles freely available online

High visibility within the field

- Retaining the copyright to your article

Submit your next manuscript at $\boldsymbol{\nabla}$ springeropen.com 